Letters to the Editor

\title{
Determination of the Complex Species of Copper(II) with Humic Acid by Batch Operation Using Cation-Exchanger Sulfopropyl Sephadex C-25
}

\author{
Mitsuhiko Taga, Shunitz TANaka and Masami Fukushima \\ Faculty of Science, Department of Chemistry, Hokkaido University, Sapporo 060, Japan
}

Keywords Copper, humic acid, sulfopropyl Sephadex C-25, batch operation

Heavy metal ions exist in various forms in natural waters. ${ }^{1}$ The knowledge about these forms is important for biological and environmental aspects. ${ }^{2}$ Therefore, simple, rapid and sensitive methods to determine both the free metal ions and the complexed metal species distinguishably are necessary for the speciation analysis of heavy metal ions in natural waters containing organic ligands such as humic substances. Recently, many methods for the speciation have been reported: for example, ion selective electrodes (ISE) ${ }^{3}$, anodic stripping voltammetry $(\mathrm{ASV})^{4}$, dialysis membrane ${ }^{5}$ and so on. Methods using ion-exchanger columns have also been reported. A nonionic styrene/divinylbenzene copolymer Amberlite XAD-2, an anion-exchanger Sepha$\operatorname{dex}$ A-25 (A-25), and the chelate resin Chelex-100 columns have been used. ${ }^{6-8}$ Similarly, the strong acid cation-exchanger gel, sulfopropyl Sephadex C-25 (C-25) column was used for the separation of cationic species of copper in natural waters. ${ }^{9}$ The evaluation of copper complexing ability of humic acid by the A-25 column has also been reported. ${ }^{10,11}$ In that method, a copper(II)-humic acid complex was retained on the A-25, and free copper ion amount in the effluent was measured by atomic absorption spectrometry (AAS). However, when the fraction of free copper ion is very small owing to the presence of ligand in a large excess, it is difficult to measure the free copper ion amount in effluent.

In present work, C-25 was used and the batch operation for the separation of the complex species of copper with humic acid was investigated. In the batch operation, the free copper ion was retained on the C-25 and the stable anionic species, such as a copper-humic acid complex, were separated in the supernatant. The amount of copper in the supernatant was measured by flame AAS. By this method, the complex species of copper with humic acid or nitrilotriacetic acid (NTA) were more simply measured. The concentration of the free copper ion calculated from these values was in good agreement with those obtained by ISE method. It was confirmed that this batch operation using the C-25 was a simple and rapid method for the evaluation of the copper complexing ability of humic acid.

\section{Experimental}

A humic acid solution was prepared by dissolving the humic acid powder (Fluka Chemie AG.) in potassium hydroxide. A copper standard solution was prepared by dissolving the electrolytic copper (purity $99.999 \%$, Mitsuwa Pure Chemicals) in nitric acid. A sulfopropyl Sephadex C-25 (Pharmacia Biochemistry LKB, $\mathrm{Na}^{+}$ form) was washed with $0.1 \mathrm{M}$ hydrochloric acid, and washed with water several times. The C-25 gel and a $1 \mathrm{M}$ potassium acetate were shaken for $10 \mathrm{~min}$ in a centrifuge tube, and then centrifugation was performed for $10 \mathrm{~min}$. This procedure was repeated 5 times to convert the $\mathrm{C}-25$ into $\mathrm{K}^{+}$form and the $\mathrm{C}-25$ was washed with water several times. Zero point four milliliters of the C-25 was packed in the column $(40 \mathrm{~mm} \times 8 \mathrm{~mm}$ i.d., Bio Rad). The C-25 column was washed with water; the buffer solution was passed through at the same $\mathrm{pH}$ as the sample solution, and then the water between gel particles was excluded by suction. The under cap was put on, and $5 \mathrm{ml}$ of sample solution containing copper and organic ligands was pipetted into the C-25 column. The upper cap was put on, and the C-25 column was shaken for 2 min by a shaker (IWAKI Co., Ltd.) and kept for about $30 \mathrm{~min}$. One hundred microliters of supernatant was injected into a Teflon funnel connected to the nebulizer needle of flame atomic absorption spectrometer (HITACHI 170-50 type). Copper in the supernatant was measured at $324.7 \mathrm{~nm}$ by an air/acetylene flame. A copper ion selective electrode (HORIBA 8006-05T type) was also used to determine the concentration of free copper ion in the sample solution. Before using ISE, a Nernstian response was ascertained in the range of $10^{-6}$ to $10^{-2} \mathrm{M}$ for the concentration of copper ion. The ISE responds to the activity of free copper ion. But in this work, the activity was approximated to the molar concentration of free copper ion. 


\section{Results and Discussion}

\section{Adsorption behavior of copper ion on $\mathrm{C}-25$}

When the acetate buffer solution at the $\mathrm{pH}$ of 4.5 or 6 containing copper(II) ions alone was shaken with the C-25, copper was not detected in the supernatant at all. Therefore, all of free copper ion was retained on the C-25. The investigation on the effect of shaking time (investigated for 1 to $60 \mathrm{~min}$ ) showed that all of the copper ion was retained on the C-25 within $1 \mathrm{~min}$. Therefore, it seemed that the ion-exchange equilibrium between the copper(II) and the sulfopropyl group in the $\mathrm{C}-25$ was achieved rapidly.

On the other hand, when the copper solution in the presence of humic acid or NTA as a model ligand was shaken with the C-25, copper was detected in the supernatant. It seemed that the copper which remained in the supernatant was the copper complex species with humic acid or NTA, because these complexes were anionic species and could not be retained on the C-25. The amount of copper in the supernatant was constant, independent of the shaking time for 1 to $60 \mathrm{~min}$. This fact suggests that the dissociation of the copper complex with these ligands did not occur during cationexchange. Therefore, this batch operation using C-25 can be applied to measure the copper complex species with humic acid or NTA.

\section{Determination of the copper species with humic acid}

A free copper ion was retained on C-25 as described above. The copper found in the supernatant is attributed to the copper species with humic acid or NTA. The concentration of the free copper ion could be estimated by subtracting the copper concentration of the supernatant from the total copper concentration of the original solution. The values were compared with those by ISE method that responded to free copper ion (Table 1). In the present method, the relative standard deviations (RSD) of the measurement were less than $2 \%(n=5)$. The values obtained by this method were in good agreement with ISE method. However, in case of the lower copper concentration in the sample solution, the free copper ion hardly could be detected by ISE, since the copper mostly existed as the complex form with humic acid or NTA. The conditional stability constant of copper-NTA complex at pH of 4.5 was measured by a Scatchard plot as we showed previously. ${ }^{11}$ The value estimated was $5.8\left(\log K^{\prime}\right)$ and in good agreement with the literature values. ${ }^{12,13}$ On the other hand, it was known that the concentration of humic substances in the peat soil water was in the range of 10 to $30 \mathrm{mg} / 1$ in Hokkaido. ${ }^{14}$ Therefore, the present method could be directly applied to the measurement of the copper complexing ability of such peat soil water. This batch operation using the $\mathrm{C}-25$ was simple, rapid and appropriate to routine work. The batch operation has also an advantage that the procedure for the separation can be performed instantly at the sampling spot. Some studies of complexing equilibria between
Table 1 Concentration of copper species in the presence of humic acid (HA) or NTA $(n=5)$

\begin{tabular}{|c|c|c|c|c|c|}
\hline \multirow{2}{*}[L]{$^{\mathrm{a}}$} & \multirow{2}{*}{$\mathrm{pH}$} & \multirow{2}{*}{$\begin{array}{c}{[\mathrm{Cu}]_{\mathrm{t}}^{\mathrm{b}} /} \\
\boldsymbol{\mu} \mathrm{M}\end{array}$} & \multicolumn{2}{|c|}{ C-25 method } & \multirow{2}{*}{$\frac{\text { ISE method }}{[\mathrm{Cu}] / \mu \mathrm{M}}$} \\
\hline & & & {$[\mathrm{CuL}]^{c} / \mu \mathrm{M}$} & {$[\mathrm{Cu}]^{\mathrm{d}} / \mu \mathrm{M}$} & \\
\hline \multicolumn{6}{|l|}{ NTA } \\
\hline \multirow{3}{*}{$10 \mu \mathrm{M}$} & 4.5 & 15.9 & 8.4 & 7.5 & 6.7 \\
\hline & 4.5 & 3.18 & 2.6 & 0.5 & $N^{e}$ \\
\hline & 4.5 & 1.59 & 1.4 & 0.2 & ND \\
\hline \multirow[t]{2}{*}{$5 \mu \mathrm{M}$} & 6 & 15.9 & 5.3 & 11 & 11 \\
\hline & 4.5 & 15.9 & 4.2 & 9.2 & 8.6 \\
\hline \multicolumn{6}{|l|}{ HA } \\
\hline \multirow[t]{5}{*}{$35.2 \mathrm{mg} / \mathrm{l}$} & 6 & 15.9 & 6.7 & 9.2 & 9.6 \\
\hline & 6 & 2.38 & 1.9 & 0.5 & ND \\
\hline & 6 & 1.59 & 1.4 & 0.2 & ND \\
\hline & 5 & 15.9 & 4.9 & 11 & 11 \\
\hline & 4 & 15.9 & 1.9 & 14 & 14 \\
\hline \multirow[t]{2}{*}{$11.7 \mathrm{mg} / 1$} & 6 & 15.9 & 4.9 & 11 & 11 \\
\hline & 4.5 & 15.9 & 0.9 & 15 & 15 \\
\hline
\end{tabular}

a. NTA or HA concentration in the sample solution.

b. Copper concentration in the sample solution.

c. Concentration of copper species with NTA or HA.

d. Concentration of free copper ion.

e. Not detected.

copper and humic substances in natural waters or peat soil are in progress which employ this method.

\section{References}

1. S. Faust and J. V. Hunter, "Organic Compounds in Aqueous Environment", p. 239, Marcel Dekker, New York, 1971.

2. E. W. Davey, M. J. Morgan and S. J. Erickson, Limnol. Oceanogr., 18, 993 (1973).

3. J. Buffle, F.-L. Greter and W. Haerdi, Anal. Chem., 49, 216 (1977).

4. J. E. Gregor, H. Kipton and J. Powell, Anal. Chim. Acta, 211, 141 (1988)

5. R. E. Truitt and J. H. Weber, Anal. Chem., 53, 337 (1981).

6. M. Hiraide, Y. Arima and A. Mizuike, Anal. Chim. Acta, 200, 171 (1987).

7. M. Hiraide, S. P. Tillekeratne, K. Otsuka and A. Mizuike, Anal. Chim. Acta, 172, 215 (1985).

8. R. J. Stolzberg and D. Rosin, Anal. Chem., 49, 226 (1977).

9. T. Miwa, M. Murakami and A. Mizuike, Anal. Chim. Acta, 219, 1 (1989).

10. M. Hiraide, F.-L. Ren, R. Tamura and A. Mizuike, Mikrochim. Acta[Wien], 1987II, 137.

11. M. Taga, S. Tanaka and M. Fukushima, Anal. Sci., 5, 597 (1989).

12. S. Tanaka, Y. Morimoto, M. Taga and H. Yoshida, Talanta, 30, 867 (1983).

13. Y. Liu and J. D. Ingle, Jr., Talanta, 36, 185 (1989).

14. T. Yotsuyanagi and K. Gotoh, "Mizu no Bunseki (Water Analysis, in Japanese)", 3rd ed., p. 373, Kagakudojin, Kyoto, 1981. 